\title{
ANALISIS STRATEGI PERUBAHAN BISNIS PT BATA INDONESIA
}

\author{
Pamungkur \\ Email : pamungkur@gmail.com \\ Sunarmie \\ Email : sunarmie@gmail.com \\ STIE Palangka Raya
}

\begin{abstract}
PT. Bata Indonesia is a company engaged in footwear manufacturing and retail industry. The increasing competition in today's business world becomes a challenge for the company to keep competing and surviving in the competition.

The research method used in this research is descriptive method with case-study research type. The research data collection technique is survey which was carried through interviews and questionnaires with the company director and general service manager of the sales department. The collection of data obtained was analyzed using SWOT analysis. For in order to make an accurate strategy for a company to run, it is necessary to begin with reviewing the company's strengths, weaknesses, opportunities, and also threats for the company.

From the SWOT analysis undertaken, it was figured that the IFAS value is 2,64584 and the EFAS value is 2,32827. Moreover, the IE matrix showed that the company's position is in the concentration strategy through horizontal integration or stability. This is a state where the company is experiencing a period of growth. These results inferred that the fittest strategy the company should implement is a growth strategy through horizontal integration. It is an activity to expand the company by building outlets, stores, and mall sales in as many cities as possible in Indonesia, and also to improve the products through product innovations. The result of SWOT diagram also showed that the company carries out aggressive strategy or at quadrant 1 that possesses positive value.
\end{abstract}

From the research results, it can be concluded that the company should implement SO (Strengths-Opportunities) strategy for the company to maintain the ability to survive in the business competition.

Keywords: Analysis, Business Strategy, SWOT 


\section{PENDAHULUAN}

Setiap perusahaan tentunya memiliki strategi masing-masing dalam berbisnis. Permasalahannya adalah tepatkah strategi itu dipergunakan oleh perusahaan tersebut. Karena bila ternyata strategi yang diterapkan oleh perusahaan tersebut tidak sesuai dengan keadaannya, maka strategi tersebut akan mengakibatkan kegagalan bagi perusahaan tersebut.

Strategi yang akan dibahas adalah tentang perkembangan daripada perusahaan itu sendiri dan keluaran yang dihasilkan. Hal ini tergantung tentunya pada faktorfaktor internal dan eksternal perusahaan. Faktor internal perusahaan adalah kekuatan dan kelemahan perusahaan, sedangkan faktor eksternal perusahaan adalah peluang dan ancaman yang akan dihadapi oleh perusahaan.

Penulisan ini didasarkan pada hasil penelitian yang dilakukan untuk mengenali, menganalisis, dan memahami implikasi dari penerapan suatu strategi perubahan bisnis tertentu. PT. Bata Indonesia adalah perusahaan yang melakukan penjualan produk-produk sepatu dan sandal, penelitian yang dilakukan pada perusahaan ini akan menghasilkan data yang akan diolah sehingga menghasilkan informasi yang bermanfaat.

\section{TUJUAN PENELITIAN}

Tujuan penelitian ini adalah : (1) Untuk menganalisis aspek internal dan eksternal PT. Bata Indonesia (2) Untuk mengetahui kekuatan, kelemahan, peluang serta ancaman yang dihadapi PT. Bata Indonesia dalam menjalankan strateginya (3) Dapat mengetahui strategi yang dapat dijalankan oleh PT. Bata Indonesia dalam meningkatkan penjualannya dengan menganalisa SWOT perusahaan.

\section{TINJAUAN PUSTAKA}

\section{Pengertian Dan Konsep Strategi}

Menurut Stoner, Freeman, dan Gilbert. Jr (2001), konsep strategi 
dapat didefinisikan berdasarkan dua perspektif yang berbeda yaitu : (1) dari perspektif apa suatu organisasi ingin dilakukan (intends to do), dan (2) dari perspektif apa yang organisasi akhirnya lakukan (eventually does).

Berdasarkan perspektif yang pertama, strategi dapat didefinisikan sebagai program untuk menentukan dan mencapai tujuan organisasi dan mengimplementasikan misinya. Makna yang terkandung dari strategi ini adalah bahwa para manajer memainkan peranan penting yang aktif, sadar dan rasional dalam merumuskan strategi organisasi. Dalam lingkungan yang turbulen dan selalu mengalami perubahan, pandangan ini lebih banyak diterapkan.

\section{Sedangkan}

berdasarkan perspektif kedua, strategi didefinisikan sebagai pola tanggapan atau respon organisasi terhadap lingkungannya sepanjang waktu. Pada definisi ini, setiap organisasi pasti memiliki strategi, meskipun strategi tersebut tidak pernah dirumuskan secara eksplisit. Pandangan ini diterapkan bagi para manajer yang bersifat reaktif, yaitu hanya menanggapi dan menyesuaikan diri terhadap lingkungan secara pasif manakala dibutuhkan.

Strategi merupakan cara untuk mencapai sasaran jangka panjang. Strategi yang digunakan dalam menjalankan kegiatan usaha dapat termasuk perluasan geografis, diversifikasi, akuisisi, pengembangan produk, penetrasi pasar, pengurangan, divestasi, likuidasi, dan usaha patungan. Sasaran dapat ditentukan sebagai hasil yang spesifik yang ingin dicapai sebuah organisasi dengan melakukan misi dasarnya. Jangka panjang berarti lebih dari satu tahun. Sasaran perlu untuk keberhasilan organisasi karena menyatakan arah, membantu dalam evaluasi, menciptakan sinergi, mengungkapkan prioritas, memfokuskan koordinasi, dan menyediakan dasar 
untuk perencanaan, Porter dalam Hariadi, Bambang pengorganisasian, memotivasi, dan (2003) pola umum peta persaingan mengendalikan aktivitas secara dalam pasar biasanya melibatkan efektif. Sasaran harus menantang, lima kekuatan yang masing-masing dapat diukur, konsisten, pantas, dan saling menekan untuk memperoleh jelas.

keuntungan yang maksimal.

\section{Strategi Bersaing}

Menurut Tunggal (2004) bahwa

Suatu perusahaan dikatakan mempunyai keunggulan bersaing bilamana memiliki sesuatu yang lebih atas pesaingnya dalam menarik konsumen dan mempertahankan diri atas kekuatan persaingan yang mencoba menekan perusahaan. Startegi bersaing perusahaan merupakan langkah-langkah strategis yang terencana maupun yang tidak terencana untuk dapat memiliki keunggulan bersaing sehingga dapat menarik perhatian dari konsumen.

Keunggulan bersaing dalam pasar akan memudahkan perusahaan untuk meraih keuntungan lebih besar daripada pesaing dan memberikan kesempatan hidup lebih lama dalam persaingan. Menurut Michael E. kekuatan-kekuatan bersaing yang terbesar menentukan kemampulabaan dari suatu industri, dengan demikian merupakan kepentingan yang paling besar dalam formulasi strategi. Setiap industri mempunyai struktur yang mendasar atau sekumpulan karakteristik ekonomi teknis dasar yang menimbulkan kekuatan bersaing tersebut. Beberapa karakteristik adalah krtikal terhadap kekuatan dari setiap kekuatan bersaing.

\section{METODOLOGI PENELITIAN}

\section{Jenis dan Metode Penelitian}

Dalam melakukan penelitian ini, peneliti menggunakan metode deskriptif adalah penelitian yang dilakukan untuk mengetahui nilai 
variabel mandiri atau lebih (independen) tanpa membuat perbandingan, atau menghubungkan dengan variabel yang lain. Dalam jenisnya penelitian ini menggunakan studi kasus.

\section{Teknik Pengumpulan Data}

Dalam pengumpulan data, yang diolah dan disusun sesuai dengan analisis ini, pengumpulan data melalui (a) Penelitian kepustakaan (library research) yaitu Metode dilakukan untuk mendapatkan data-data yang sifatnya teoritis. Dilakukan dengan cara membaca dan mempelajari buku-buku ilmiah, Jurnal publikasi, karya tulis, artikel, serta data-data lain yang berhubungan dengan pembahasan yang disusun (b) Penelitian lapangan (field research) yaitu mengumpulkan data dengan cara berhubungan langsung dengan keadaan yang sebenarnya, dengan jalan wawancara dan pengamatan.
3. Definisi Operasional dan Instrumen Pengukuran

Sekaran (2000) berpendapat mengoperasikan suatu konsep agar dapat diukur, dikerjakan dengan cara mengamati dimensi perilaku yang tersirat dalam suatu konsep, yang mana kemudian diterjemahkan menjadi elemen-elemen yang dapat diamati dan diukur dengan mendefinisikan suatu konsep agar dapat dioperasikan melibatkan beberapa tahap, yaitu dengan mengetahui terlebih dahulu variabel, dimensi, dan indikatornya.

Instrumen pengukuran yang digunakan adalah untuk mengukur faktor internal, yaitu kekuatan dan kelemahan perusahaan, serta faktor eksternal, yaitu peluang dan ancaman dalam bentuk kuisioner. Adapun angka untuk pemberian bobot baik untuk faktor internal maupun faktor ekternal adalah sebagai berikut (1) Pengaruhnya kecil (2) Pengaruhnya sedang (3) Pengaruhnya paling besar. 
Pembagian nilai rating pada faktor internal adalah (1) Kelemahan utama (2) Kelemahan kecil (3) Kekuatan kecil (4) Kekuatan utama. Sedangkan pemberian nilai rating pada faktor eksternal adalah (1) Ancaman utama (2) Ancaman kecil (3) Peluang Kecil (4) Peluang utama.

\section{Analisis SWOT}

Analisis ini dilakukan untuk mengidentifikasi kekuatan (Strengths), kelemahan (Weakness) dalam lingkungan internal perusahaan, dan peluang (Opportunities) serta ancaman (Threats) lingkungan eksternal perusahaan. Analisis kekuatan dan kelemahan yang ada di lingkungan internal terutama ditujukan terhadap faktor keberhasilan kunci (Key Success Factor). Jadi dengan analisis ini diharapkan akan diperoleh cara untuk mengembangkan dan memanfaatkan kekuatan serta penopang atau mengurangi kelemahan dengan maksud untuk memanfaatkan peluang dan mengurangi ancaman.

Dari analisis ini ada empat kemungkinan identifikasi lingkungan yang dihadapi perusahaan (a) Terdapat peluang dalam suatu industri dan perusahaan mempunyai kekuatan untuk mendapatkannya sehingga harus disusun strategi yang bersifat agresif (b) Terdapat peluang dalam suatu industri akan tetapi perusahaan mempunyai kelemahan yang pokok untuk mendapatkannya, sehingga harus disusun strategi yang bersifat perubahan haluan (Turnaround) (c) Terdapat ancaman dalam suatu industri dan perusahaan mempunyai kekuatan untuk mendapatkannya, sehingga harus disusun strategi bisnis yang bersifat diversifikasi (d) Terdapat ancaman dalam suatu industri dan disamping itu perusahaan mempunyai kelemahan yang pokok di bidang yang bersangkutan, sehingga harus disusun strategi yang bersifat defensif. 


\section{Teknik Analisis Data}

Teknik

analisis

data

menggunakan statistik deskriptif.

Statistik deskriptif adalah statistik

yang digunakan untuk menganalisa

data dengan cara mendeskripsikan

atau menggambarkan data yang

telah terkumpul sebagaimana

adanya tanpa bermaksud membuat

kesimpulan yang berlaku untuk

umum atau generalisasi. Statistik

deskriptif juga melakukan prediksi

dengan analisis regresi, dan

membuat perbandingan dengan

membandingkan rata-rata data

sampel atau populasi.

\section{HASIL PENELITIAN}

Mengidentifikasikan

lingkungan internal meliputi kekuatan dan kelemahan, dan lingkungan eksternal yang meliputi peluang dan ancaman, maka telah dilakukan wawancara langsung dengan pihak-pihak yang terkait dengan penelitian ini.

Tujuan dari pembagian kuesioner ini adalah untuk mendapatkan berbagai rincian mengenai faktor internal yang terdiri dari kekuatan dan kelemahan perusahaan dan faktor eksternal yang meliputi peluang dan ancaman bagi perusahaan. Jawaban sebagai berikut :

\section{Rekapitulasi Faktor Kekuatan Internal}

Tabel 1. Rekapitulasi Faktor

Kekuatan Internal

\begin{tabular}{|c|l|}
\hline No & \multicolumn{1}{|c|}{\begin{tabular}{c}
\multicolumn{1}{|c|}{ paktor kekuatan } \\
perusaan
\end{tabular}} \\
\hline 1 & $\begin{array}{l}\text { Produk yang memiliki } \\
\text { kualitas yang baik }\end{array}$ \\
\hline 2 & $\begin{array}{l}\text { Harga produk yang relatif } \\
\text { stabil }\end{array}$ \\
\hline 3 & Adanya layanan purna jual \\
\hline 4 & $\begin{array}{l}\text { Lokasi perusahaan yang } \\
\text { strategis }\end{array}$ \\
\hline 5 & $\begin{array}{l}\text { Adanya brand image yang } \\
\text { baik }\end{array}$ \\
\hline
\end{tabular}

Sumber : Hasil Kuesioner PT. Bata Indonesia (2017) 
2. Rekapitulasi Faktor Kelemahan Internal

Tabel 2. Rekapitulasi Faktor

Kelemahan Internal

\begin{tabular}{|c|l|}
\hline No & \multicolumn{1}{|c|}{ Faktor Kelemahan } \\
& \multicolumn{1}{|c|}{ Perusahaan } \\
\hline 1 & $\begin{array}{l}\text { Model Kurang Mengikuti } \\
\text { Trend Pasar }\end{array}$ \\
\hline 2 & $\begin{array}{l}\text { Kurangnya Disiplin } \\
\text { Karyawan }\end{array}$ \\
\hline 3 & $\begin{array}{l}\text { Keterlambatan Pengiriman } \\
\text { Barang Ke Luar kota }\end{array}$ \\
\hline 4 & $\begin{array}{l}\text { Pembagian Tugas Kerja } \\
\text { Yang Tidak Teratur }\end{array}$ \\
\hline 5 & $\begin{array}{l}\text { Kerusakan Barang Pada Saat } \\
\text { Pengiriman }\end{array}$ \\
\hline
\end{tabular}

Sumber : Hasil Kuesioner PT. Bata Indonesia (2017)

\section{Rekapitulasi Faktor Peluang}

\section{Eksternal}

Tabel 3. Rekapitulasi Faktor

Peluang Eksternal

\begin{tabular}{|c|l|}
\hline No & Faktor Peluang Perusahaan \\
\hline 1 & Pangsa Pasar Yang Luas \\
\hline 2 & $\begin{array}{l}\text { Perkembangan Dunia Mode } \\
\text { Yang Pesat }\end{array}$ \\
\hline
\end{tabular}

\begin{tabular}{|c|lr|}
\hline 3 & Adanya r Penawaran \\
& $\begin{array}{l}\text { Kerjasama } \\
\text { Perusahaan Lain }\end{array}$ \\
\hline 4 & $\begin{array}{l}\text { Munculnya Pusat - Pusat } \\
\text { Perbelanjaan baru }\end{array}$ \\
\hline 5 & $\begin{array}{l}\text { Peluang Untuk Melakukan } \\
\text { Ekspor }\end{array}$ \\
\hline
\end{tabular}

Sumber : Hasil Kuesioner PT. Bata Indonesia (2017)

\section{Rekapitulasi Faktor Ancaman Eksternal}

Tabel 4. Rekapitulasi Faktor Ancaman Eksternal

\begin{tabular}{|c|l|}
\hline No & \multicolumn{1}{|c|}{\begin{tabular}{c}
\multicolumn{1}{|c|}{ Paktor Ancaman } \\
Perusahaan
\end{tabular}} \\
\hline 1 & $\begin{array}{l}\text { Banyaknya Pendatang Baru } \\
\text { Perpindahan Sumber Daya } \\
\text { Manusia }\end{array}$ \\
\hline 3 & $\begin{array}{l}\text { Situasi Politik Yang tidak } \\
\text { Menentu }\end{array}$ \\
\hline 4 & Adanya Produk Peniru \\
\hline 5 & $\begin{array}{l}\text { Keterlambatan Pengiriman } \\
\text { Produk Dari Pabrik }\end{array}$ \\
\hline
\end{tabular}

Sumber : Hasil Kuesioner PT. Bata Indonesia (2017) 


\section{Hasil Kuesioner Pembobotan} Faktor Internal dan Eksternal

Untuk langkah selanjutnya dalam tahap pengumpulan data, yaitu dengan mengunakan kuesioner pembobotan faktor internal dan faktor eksternal untuk menentukan bobot pada faktor internal dan eksternal.

\section{Tahap I : Tahap Input Data}

Setelah data-data yang dibutuhkan terkumpul, selanjutnya menginput data-data tersebut dalam penentuan bobot dengan perbandingan berpasangan baik untuk faktor internal maupun untuk faktor eksternal. Kemudian hasilhasil dari tabel penentuan bobot tersebut dinormalisasi agar dapat diperoleh bobot akhir yang akan dipergunakan dalam matriks IFAS dan matriks EFAS.

\subsection{Matriks IFAS (Internal Faktor} Analysis Summary)

Didalam Matrik IFAS ini, data yang diperoleh adalah data yang berasal dari Tabel normalisasi bobot faktor internal dan juga data yang diperoleh dari kuesioner penilaian skor faktor internal perusahaan.

\subsection{Matriks EFAS (External Factor} Analysis Summary)

Didalam matrik EFAS ini, data yang diperoleh adalah data yang berasal dari tabel normalisasi bobot faktor eksternal dan data yang diperoleh dari kuesioner penilaian faktor eksternal perusahaan.

\section{Tahap II : Tahap Pencocokan}

\section{Data Perusahaan}

Dalam tahap pencocokan ini, digunakan dua metode, yaitu: matriks internal eksternal dan diagram matriks SWOT. Hal ini dilakukan agar diperoleh strategi yang benar-benar tepat untuk dijalankan perusahaan.

\subsection{Hasil Matrik Internal Eksternal} (IE)

Berdasarkan hasil dari tabel Matrik IFAS dan tabel Matrik EFAS (tabel 10), diketahui bahwa nilai IFASnya adalah 2,64854 dan nilai EFASnya adalah 2,32827. dengan demikian PT Bata Indonesia berada 
pada sel nomor 5, yaitu suatu keadaan dimana perusahaan mengalami suatu masa pertumbuhan. Dengan demikian dapat diketahui strategi yang sebaiknya dijalankan adalah strategi pertumbuhan melalui Integrasi Horisontal.

Strategi pertumbuhan melalui Integrasi Horisontal adalah suatu kegiatan untuk memperluas perusahaan dengan cara membangun di lokasi lain, dan meningkatkan jenis produk serta jasa.

Karena perusahaan berada dalam daya tarik industri sedang, strategi yang diterapkan adalah konsolidasi. Tujuannya relatif lebih difensif, yaitu menghindari kehilangan penjualan dan kehilangan profit. Perusahaan yang berada di sel ini dapat memperluas pasar, fasilitas produksi, dan teknologi melalui pengembangan internal dan eksternal perusahaan.
8.2 Hasil Diagram SWOT

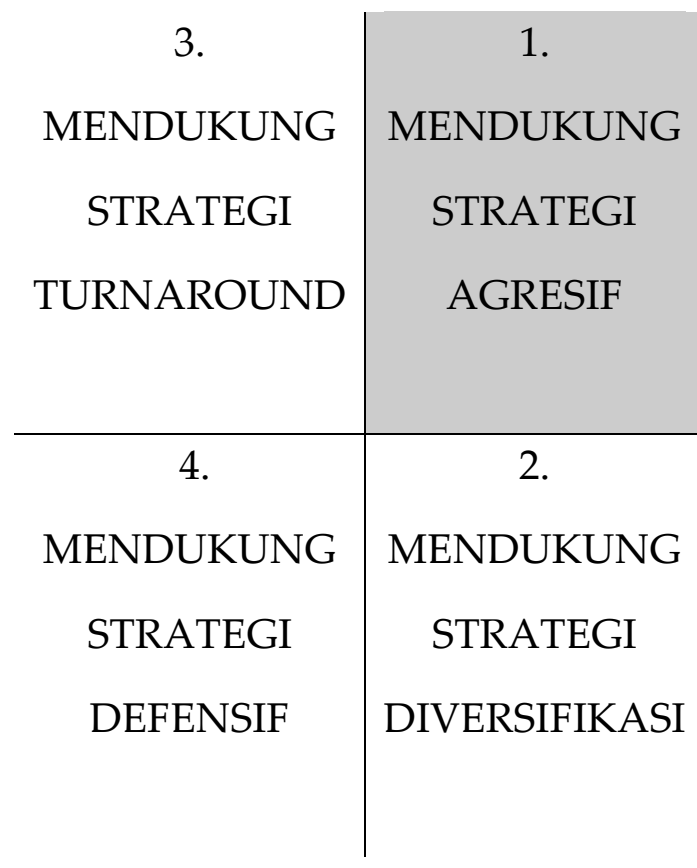

Sumber : Hasil Kuesioner PT Bata Indonesia (2017)

Berdasarkan hasil dari tabel matrik IFAS dan tabel Matrik EFAS, diketahui bahwa nilai IFAS $=2,64584$ dan nilai $\mathrm{EFAS}=2,32827$ dan juga berdasarkan perhitungan dari jumlah nilai kekuatan (S) setelah dikali dengan skor lebih besar daripada jumlah nilai kelemahan (W) setelah dikali dengan skor, yang berarti perusahaan mempunyai kekuatan dari segi internalnya. Begitu pula dengan jumlah nilai peluang $(\mathrm{O})$ setelah dikali dengan nilai skor yang lebih besar daripada 
jumlah nilai ancaman (T) setelah inovasi produk, mempertahankan dikali dengan skor, yang berarti kualitas produk dan harga yang perusahaan mempunyai banyak stabil serta memperluas jaringan peluang.

pemasaran perusahaan dan

Dengan demikian, PT Bata memanfaatkan fasilitas perusahaan Indonesia berada pada kuadran ke-1 yang ada dengan baik.

(satu), yaitu suatu keadaan dimana Untuk meningkatkan kualitas perusahaan memiliki kekuatan dari produk dan melakukan inovasi segi internal dan juga mempunyai produk perusahaan dapat banyak peluang. PT. Bata Indonesia melakukan sebagai berikut (1) harus menggunakan serta meman- Perusahaan harus selalu dapat faatkan kekuatan internalnya secara membuat inovasi terbaru dan juga maksimal dan memanfaatkan model yang lebih menarik sehingga peluang yang ada. Strategi yang tepat adalah dengan menggunakan kekuatan untuk memanfaatkan peluang jangka panjang yang besar yaitu dengan strategi agresif.

Berdasarkan diagram SWOT maka dapat diketahui bahwa perusahaan sedang menjalankan strategi SO (Strength and Opportunities) yaitu strategi dimana perusahaan menggunakan kekuatan dan peluang yang dimiliki untuk menjalankan usahanya. Dengan demikian perusahaan sebaiknya berkonsentrasi untuk melakukan membuat konsumen bangga untuk menggunakan produk tersebut (2) Perusahaan harus dapat mengantisipasi perkembangan pasar yang semakin bersaing dengan hadirnya pesaing dan pendatang baru (3) Perusahaan harus berkerja keras agar dapat menjaga kualitas dari produk yang ada untuk memenuhi standar baku perusahaan (5)Perusahaan harus dapat mempertahankan harga jual produknya yang lebih stabil sehingga dapat berpengaruh dengan 
kehadiran produk-produk lokal konsumen, hal itu dapat dilakukan yang sejenis.

Untuk memperluas jaringan penjualannya dan memaksimalkan penggunaan fasilitas, PT. Bata Indonesia dapat melakukan hal-hal berikut (1) Untuk memperluas jaringan penjualannya perusahaan harus membuka butik-butik dan outlet-outlet di kota-kota lainnya yang dianggap mempunyai pangsa pasar yang besar dan strategis dengan fasilitas pelayanan yang lengkap untuk memperluas penjualannya sehingga produknya dapat dikenal secara luas oleh konsumen (2) Fasilitas yang ada harus lebih ditingkatkan untuk mencapai hasil yang maksimal agar dapat memberikan citra yang baik kepada konsumen, sehingga secara tidak langsung dapat membantu kinerja dari perusahaan (3)Perusahaan harus terus berupaya meningkatkan tenaga pemasaran yang handal dalam melakukan tugasnya untuk menawarkan barang dan mendistribusikannya kepada dengan menawarkan produknya kepada department store yang bergerak dibidang penjualan sepatu dan sandal.

\section{PENUTUP}

\section{Kesimpulan}

Berdasarkan hasil penelitian dapat kesimpulan sebagai berikut :

1.1 Kekuatan (Strenghts) pada PT. Bata Indonesia adalah berupa: produk yang memiliki kualitas yang baik, harga produk yang relatif stabil, adanya layanan purna jual, lokasi perusahaan yang strategis, dan adanya brand image yang baik. Sehingga dengan adanya brand image dan harga produk yang relatif stabil serta ditunjang dengan kualitas produk maka akan mempunyai pengaruh yang cukup besar dalam meningkatkan kekuatan perusahaan.

1.2 Peluang (Opportunities) pada PT. Bata Indonesia adalah berupa : pangsa pasar yang luas, 
perkembangan dunia mode yang pesat, adanya penawaran kerjasama dengan perusahaan lain, munculnya pusat-pusat perbelanjaan baru, dan peluang untuk melakukan ekspor. Berdasarkan peluang-peluang yang ada di atas perusahaan dapat memasarkan produknya lebih luas kepada konsumen.

1.3 Berdasarkan IFAS (Internal Factor Analysis Summary) dan EFAS (External Factor Analysis Summary) diketahui bahwa nilai IFAS nya 2,64584 dan nilai EFAS nya 2,32827 . maka strategi yang tepat yang dapat direkomendasikan untuk PT. Bata Indonesia adalah Integrasi Horisontal yaitu memperluas perusahaan dengan cara membangun butik-butik dan outlet-outlet baru di kota-kota dan daerah-daerah.

1.4 Berdasarkan hasil dari diagram SWOT PT. Bata Indonesia berada pada kuadran ke 1, dimana memiliki kekuatan dari segi internal dan mempunyai banyak peluang, sehingga strategi yang tepat adalah dengan mengunakan kekuatan untuk memanfaatkan peluang jangka panjang yang lebih besar yaitu dengan strategi agresif.

1.5 Berdasarkan hasil matrik SWOT dapat diketahui bahwa PT. Bata Indonesia sebaiknya mengunakan strategi SO yaitu strategi yang mengunakan kekuatan untuk memanfaatkan peluang. Hasil dari matrik SWOT yang didapat berupa mempertahankan dan meningkatkan kualitas produk dengan brand image yang baik serta menambah pusat-pusat penjualan produk yang baru dan memperluas jaringan penjualan melalui ekspor.

\section{Saran}

Adapun saran-saran yang dapat diberikan oleh penulis adalah sebagai beriku t:

2.1 Strategi yang dapat diterapkan dalam kondisi ini adalah 
mendukung kebijakan pertumbuhan yang agresif (growth oriented strategy). Ini merupakan situasi yang menguntungkan perusahaan tersebut untuk memilih peluang yang ada dengan melihat kekuatan perusahaan tersebut sehingga peluang dapat dimanfaatkan secara benar dan tepat oleh perusahaan

2.2 Berdasarkan peluang yang ada dari hasil penelitian yang dilakukan penulis, PT. Bata Indonesia perlu memperluas pangsa pasarnya ke berbagai daerah yang mempunyai pangsa pasar yang potensial untuk mengembangkan jaringan penjualan serta mengembangkan produk-produknya dalam mengikuti perkembangan mode agar penjualan dapat lebih ditingkatkan

2.3 Karyawan harus dapat meningkatkan loyalitasnya terhadap perusahaan agar perusahaan dapat memaksimal- kan hasil kinerja perusahaan tersebut, dan juga perusahaan harus memperhatikan kebutuhan dari karyawan.

2.4 Perusahaan harus terus menjaga hubungan baik yang sudah terjadi dengan member-member yang ada untuk dapat menjaga citra yang baik dimata konsumen.

2.5 Perusahaan harus selalu mengikuti perkembangan mode yang ada agar produk-produk yang ada tidak ketinggalan jaman, dan perusahaan harus sering mengeluarkan koleksikoleksi produk terbaru ke butikbutik dan outlet-outlet yang ada.

2.6 Perusahaan harus dapat meminimalisir kelemahankelemahan yang ada dalam perusahaan agar dapat bersaing di dalam pasar serta harus terus melakukan inovasi-inovasi agar tidak terancam oleh pesaingpesaing yang lain. 


\section{DAFTAR PUSTAKA}

David, Fred R. (2004). Manajemen Strategis : Konsep. Seventh Edition. PT. Intan Sejati Klaten, Indonesia

Hariadi, Bambang. (2003). Strategi Manajemen. BanyuMedia Publishing, Jakarta.

Hisrich, Robert D. William P Peter. (2000). Entrepreneurship. Fourth Edition. Mc Graw Hill Companies, Singapore.

Madura, Jeff. (2001). PengantarBisnis. Edisi Pertama. Salemba Empat, Jakarta.

Rangkuti, Fredy. (2000). Analisis dan Teknik Membedah Kasus Bisnis. PT. Gramedia Pustaka Utama, Jakarta, Indonesia.

Robinson and Pearce. (2000). Strategic Management: Formulation, Implementation and Control. Seventh Edition. Mc Graw Hill Higher Education, Singapore.

Sugiyono. (2003). Metode Penelitian Bisnis. CV. Alfabeta, Bandung, Indonesia.

Supranto, J. (2003). Statistik Teori dan Aplikasi. Erlangga, Jakarta.

Suryana. (2000). Kewirausahaan. PT. Salemba Empat, Jakarta.

Tjiptono, Fandy. (2001). Strategi

Bisnis, Andi Offset, Jakarta.
Triandaru, Sigit. (2001). Ekonomi Mikro: Pendekatan Kontemporer. PT. Salemba Empat, Jakarta.

Tunggal, Amin Widjaja. (2004). Manajemen Strategik. Edisi Pertama. Harvarindo, Jakarta.

Umar, Husein. (2002). Strategic Management In Action. PT. Gramedia Pustaka Utama, Jakarta, Indonesia.

Umar, Husein. (2003). Riset Pemasaran dan Prilaku Konsumen. Cetakan Ketiga. PT. SUN, Jakarta. 